\title{
AUMENTO DA RESISTÊNCIA A CORROSÃO ÁCIDA E SALINA EM FOLHA DE ALUMÍNIO COM REVESTIMENTO EPÓXI DOURADO (GOLD FIN)*
}

Danilo Mendes Amorim ${ }^{1}$ Joao Pedro Souza Oliveira ${ }^{2}$

\begin{abstract}
Resumo
No setor de trocadores de calor para refrigeração industrial e câmaras frias o maior desafio é a corrosão do equipamento quando exposto a intempéries. Esta situação em regiões litorâneas é agravada devido ao ataque de sal e ácidos provenientes da atmosfera. Diante disto este mercado sempre procura um aumento na resistência dos componentes das unidades evaporadoras. Neste contexto as aletas, que são feitas utilizando folha de alumínio com revestimento epóxi orgânico dourado, tem papel de grande importância. O presente trabalho visa entender os mecanismos de corrosão da folha nos principais fatores, tais quais, liga, têmpera e revestimento em relação a resistência a corrosão em áreas litorâneas. Os materiais escolhidos foram as ligas 8006 e 8079, na tempera O e com revestimentos base Epóxi e Poliéster. As amostras foram ensaiadas no laboratório utilizando ensaios de corrosão salina e acida que simulam as condições encontradas.
\end{abstract}

Palavras-chave: Gold Fin; Corrosão; Estampagem; Alumínio; Trocador de calor.

\section{INCREASE RESISTANCE OF SALT AND ACID CORROSION IN ALUMINIUM SHEET WITH EPOXY GOLDEN FINISH (GOLD FIN)}

\begin{abstract}
In the heat exchangers sector for industrial refrigeration and cold storage the biggest challenge is the corrosion of equipment when exposed to weather this situation in coastal areas is exacerbated due to salt attack and from atmospheric acids. In view of this the market always demand an increase in the resistance of components of evaporator units. In this context the fins, which are made using aluminum foil with golden organic epoxy coating plays a role of great importance. This study aims to understand the sheet of corrosion mechanisms in key factors, as such, league, Tempera and coating with respect to corrosion resistance in coastal areas. The materials chosen were the alloys 8006 and 8079, in tempera and the epoxy based coatings and polyester. The samples were tested in the laboratory using salt and acid corrosion tests simulating the conditions found.
\end{abstract}

Keywords: Gold fin; Corrosion; Stamping; Heat exchanger.

1 Engenheiro de materiais pela Universidade Estadual de Ponta Grossa, Coordenador de processos, Laminação, Companhia Brasileira de Alumínio - Votorantim Metais, Alumínio, SP, Brasil.

2 Estudante de Engenharia de Materiais Universidade Estadual de Itajubá, Estagiário, Laminação, Companhia Brasileira de Alumínio - Votorantim Metais, Alumínio, SP, Brasil. 


\section{INTRODUÇÃO}

No setor de trocadores de calor para refrigeração industrial e câmaras frias o maior desafio é a corrosão do equipamento quando exposto a intempéries, esta situação em regiões litorâneas é agravada devido ao ataque de sal e ácidos provenientes da atmosfera. Mesmo o alumínio que em condições neutras é resistente a corrosão, pois tem um filme de óxido que é estável e protege o material, em ambientes ácidos e alcalinos é suscetível a degradação, pois ocorre uma dissolução do filme oxido.

Nos trocadores de calor uma das partes mais atacadas são as aletas, quem em ambientes mais agressivos, podem sofrer corrosão em demasia e consequentemente afetar a eficiência e o funcionamento do produto.

Abaixo um exemplo de uma unidade evaporadora.

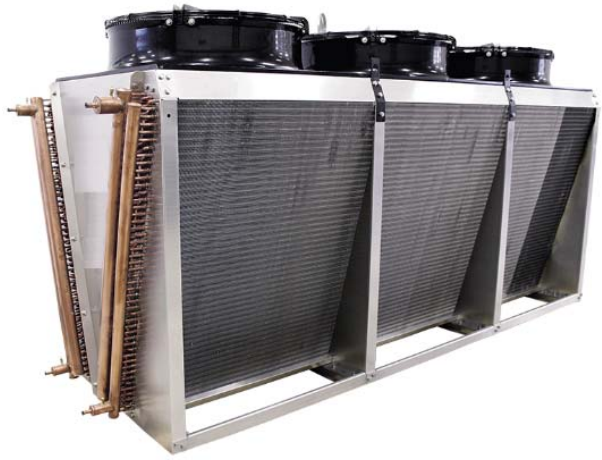

Figura 1 - Unidade evaporadora

Uma das formas de reduzir este ataque corrosivo é a utilização de revestimento ou pinturas que servem como uma película isolando o alumínio do ambiente. No entanto, esta forma de proteção abre possibilidade da corrosão filiforme que é um tipo especifico de corrosão, que ocorre na interface entre metal e revestimento. Esta corrosão é caracterizada por veios que ser formam abaixo do revestimento (fig 2).

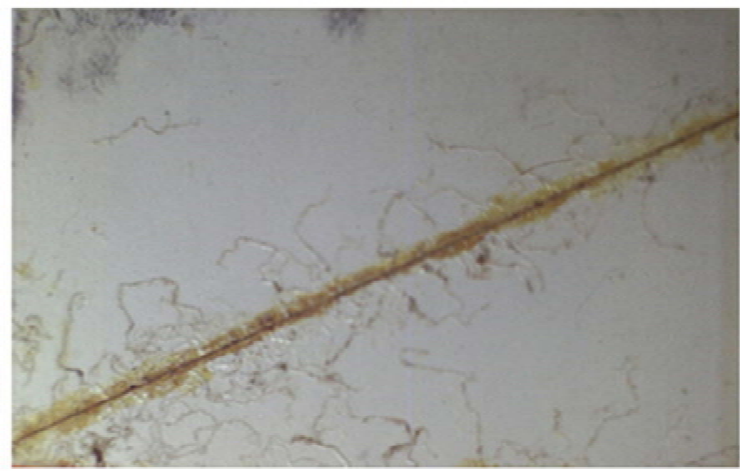

Figura 2 - Exemplo de corrosão Filiforme em chapa de aço pintada

Em trocadores de calor uma solução para a corrosão é a utilização de folha de alumínio com revestimento epóxi. Porem esta estrutura por ser revestida pode sofrer de corrosão filiforme dependendo do meio, tipo de liga usada e revestimento.

O objetivo deste trabalho é entender os mecanismos de corrosão na folha de alumínio nas ligas 8006 e 8079 , considerando os fatores: têmpera e revestimento em relação a resistência a corrosão em áreas litorâneas. 


\section{MATERIAIS E MÉTODOS}

O trabalho seguiu as etapas: confecção das amostras, avaliação das microestruturas para validar tempera, simulação das condições de corrosão e avaliação dos resultados

\subsection{Confecção das amostras}

Para a confecção das amostras foram utilizadas folhas de alumínio na espessura de 200 mícron, ligas 8079 e 8006 e tempera H19.

As amostras foram tratadas a temperatura de $400^{\circ} \mathrm{C}$ a 1 hora e revestidas usando um extensor padrão de 30 microns para simular a aplicação. Foram produzidas 8 amostras conforme tabela 1.

Tabela 1 - Amostras confeccionadas.

\begin{tabular}{|c|l|c|c|}
\hline Identificação Amostra & Liga & Tempera & Gramatura revestimento $(\mathrm{g} / \mathrm{m} 2)$ \\
\hline 1 & 8006 & $\mathrm{H} 19$ & 1,37 \\
\hline 2 & 8006 & $\mathrm{H} 19$ & 4,78 \\
\hline 3 & 8006 & $\mathrm{O}$ & 1,37 \\
\hline 4 & 8006 & $\mathrm{O}$ & 4,78 \\
\hline 5 & 8079 & $\mathrm{H} 19$ & 1,37 \\
\hline 6 & 8079 & $\mathrm{H} 19$ & 4,78 \\
\hline 7 & 8079 & $\mathrm{O}$ & 1,37 \\
\hline 8 & 8079 & $\mathrm{O}$ & 4,78 \\
\hline
\end{tabular}

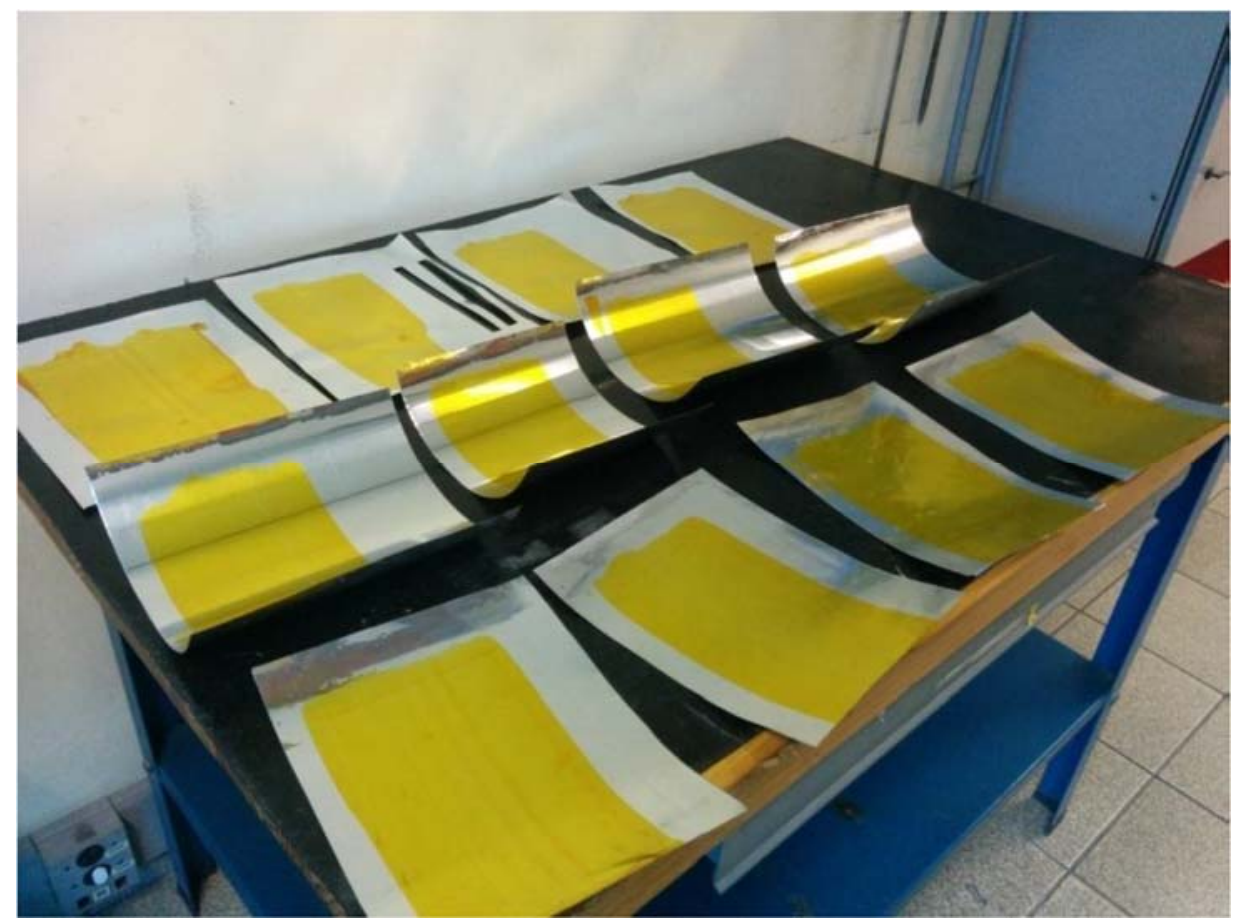

Figura 3 - Confecção das amostras

As amostras foram cortadas em padrões de $100 \times 100 \mathrm{~mm}$. Suas laterais foram protegidas para eliminar o ataque na borda da amostra. 

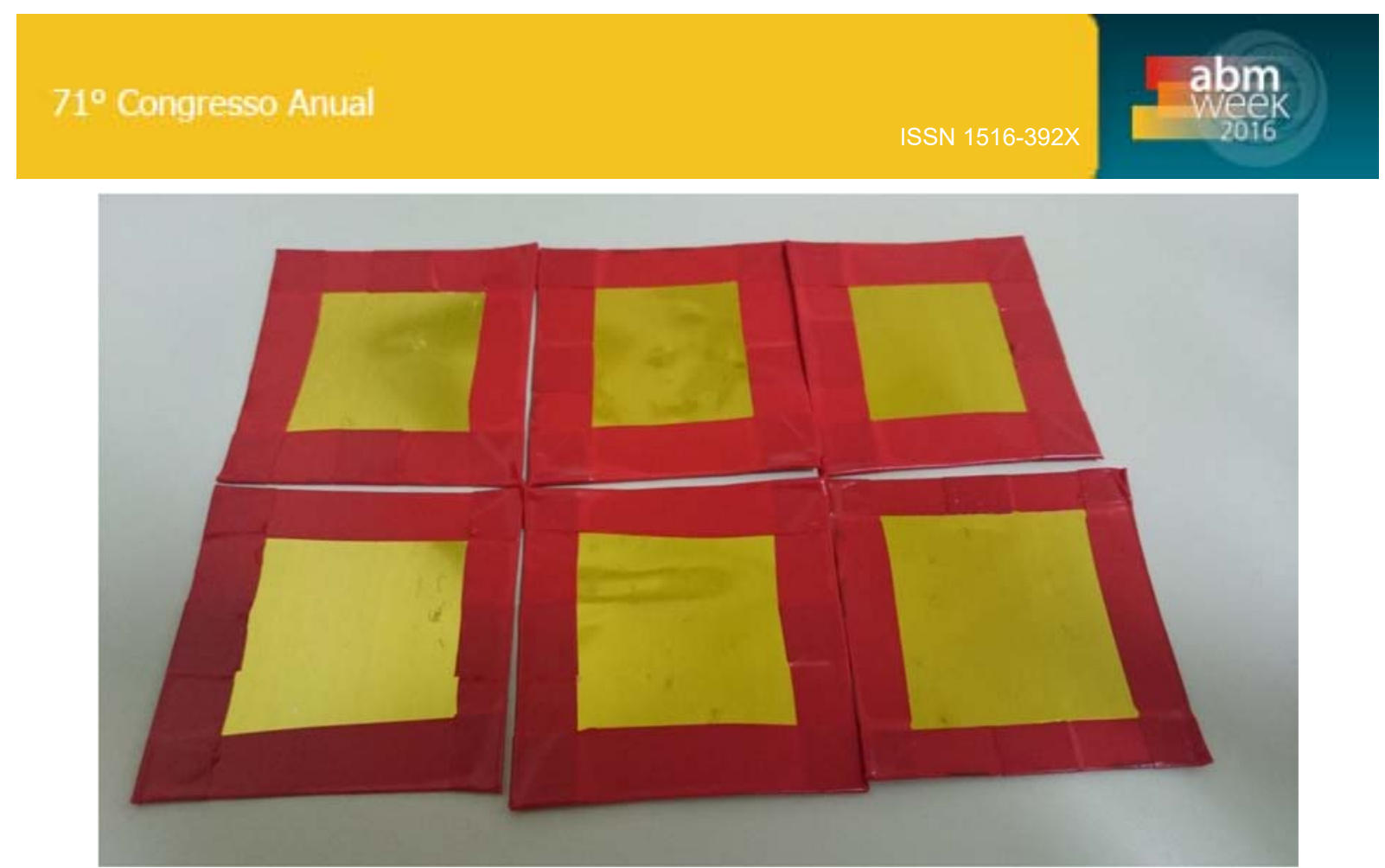

Figura 4 - amostras protegidas na lateral.

\subsection{Validação das temperas}

Para validar as têmperas foram feitos ensaios de LRT e microscopia com luz polarizada.

Verificam-se nas imagens 5 e 6 que as amostras 1, 2, 5 e 6 estão no estado H19 pois tem seus grãos alongados no sentido de laminação e nas amostras 3, 4, 7 e 8 tem grãos equiaxiais indicando um estado recozido na tempera "O".

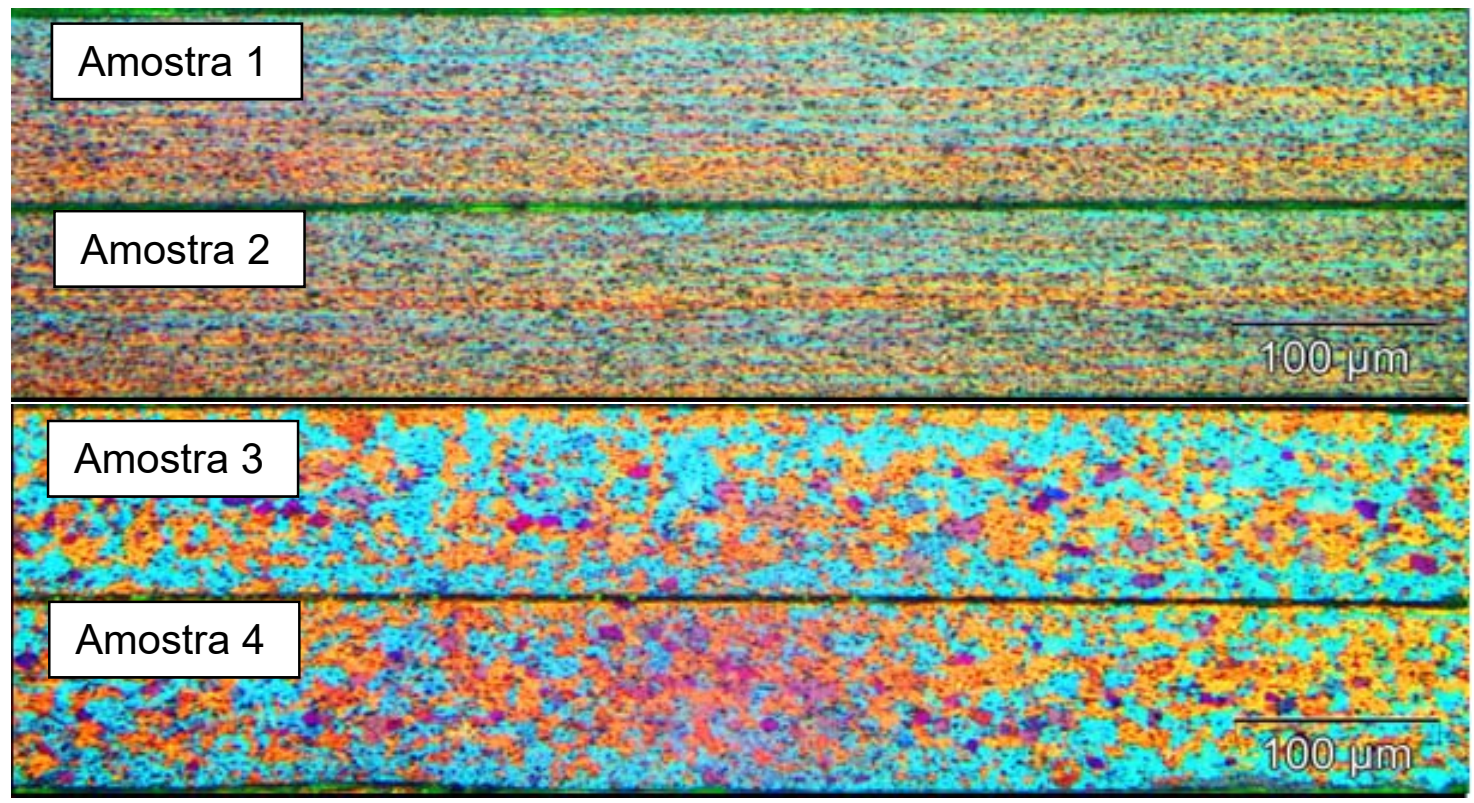

Figura 5 - Amostras 1 a 4 Liga 8006 

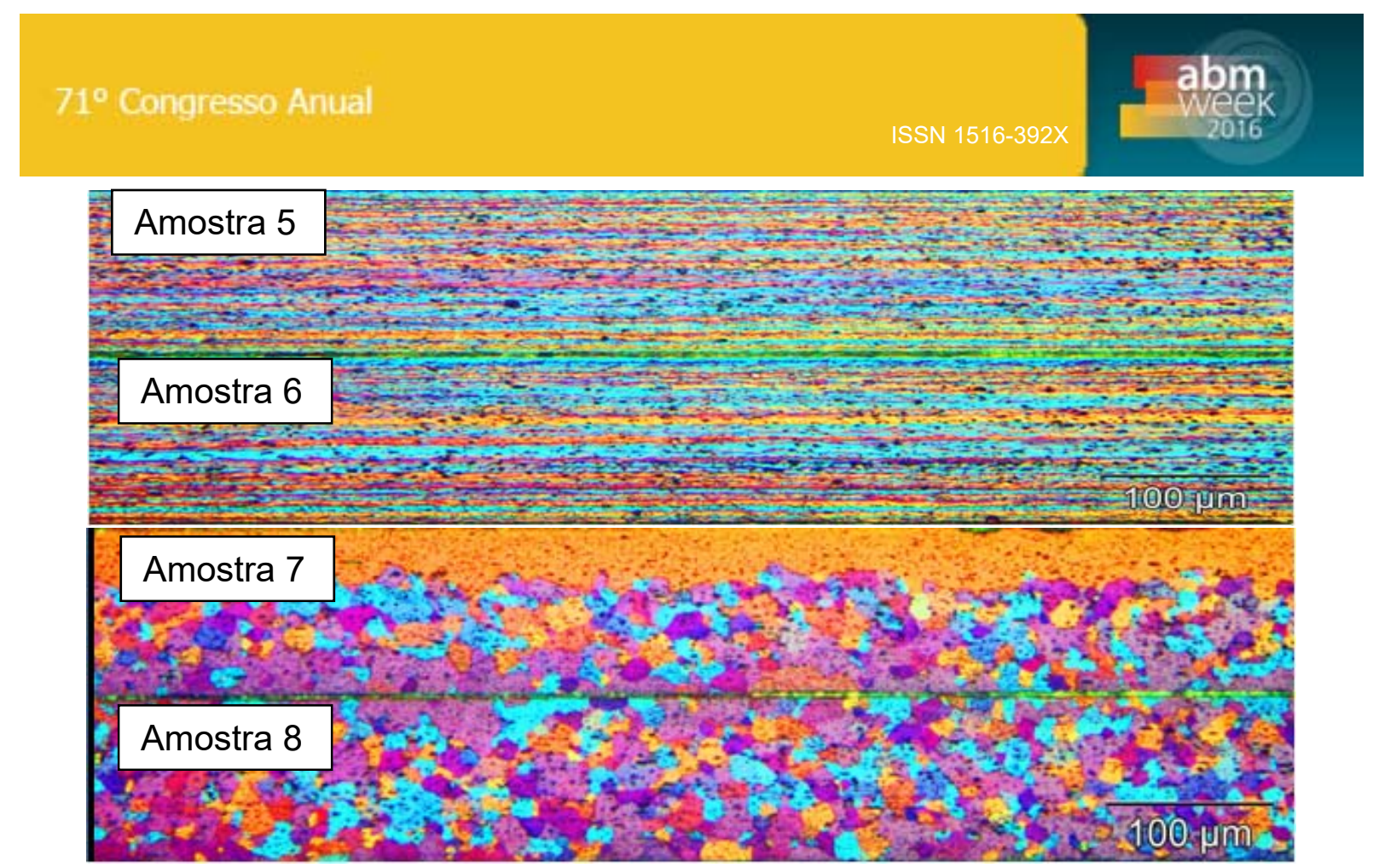

Figura 6 - Amostras 5 a 8, liga 8079

\subsection{Simulação do processo de corrosão}

Para simular a corrosão que acontece em campo foi utilizada uma receita de corrosão acelerada. Para tal foi utilizado uma solução salina-acida cuja a formulação é: 1 litro de agua destilada, $57 \mathrm{~g}$ de $\mathrm{NaCl}, 3 \mathrm{ml}$ de agua oxigenada e $7 \mathrm{ml}$ de ácido acético, sendo o ácido acético corrigido para obter o pH entre 3 e 3.

As amostras foram imersas nesta solução por um período de 6 horas a temperatura de $30^{\circ}$.

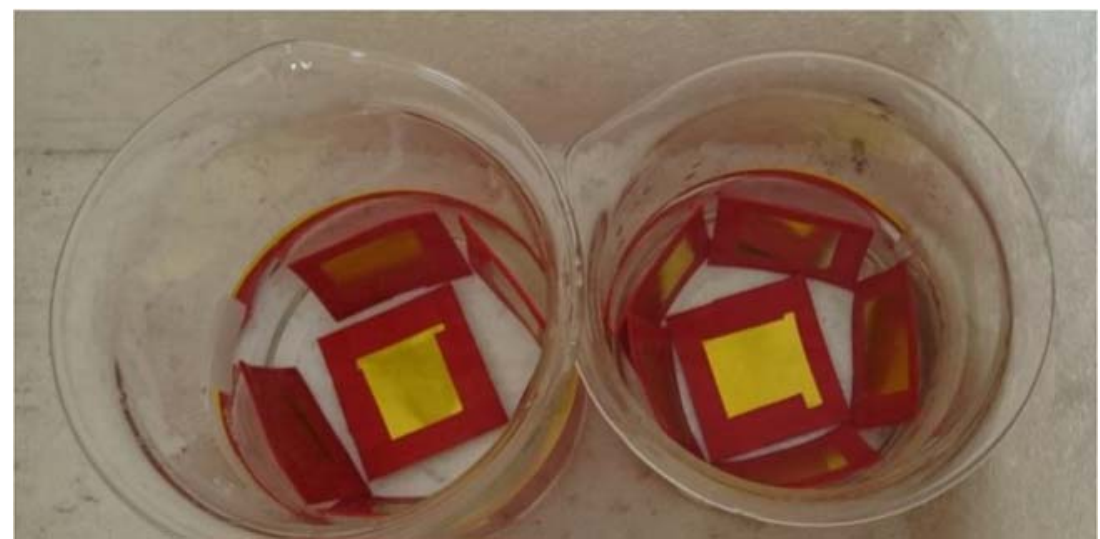

Figura 7 - Amostras 5 a 8, liga 8079

\subsection{Avaliação dos resultados}

As amostras foram avaliadas a olho nu para avaliação qualitativa da corrosão e através do microscópio ótico para avaliar no detalhe os pontos de corrosão.

\section{RESULTADOS E DISCUSSÃO}

Nas tabelas 2 e 3 temos os resultados dos ensaios. Nas amostras de número 1 a 4 referentes a liga 8006 podemos verificar que todas as amostras tiveram corrosão 
filiforme. Porem na amostra 2, com gramatura de epóxi alta, apresentou menos pontos de corrosão. Os resultados são exibidos na tabela abaixo:

Tabela 2 - Resultados - para a liga 8006

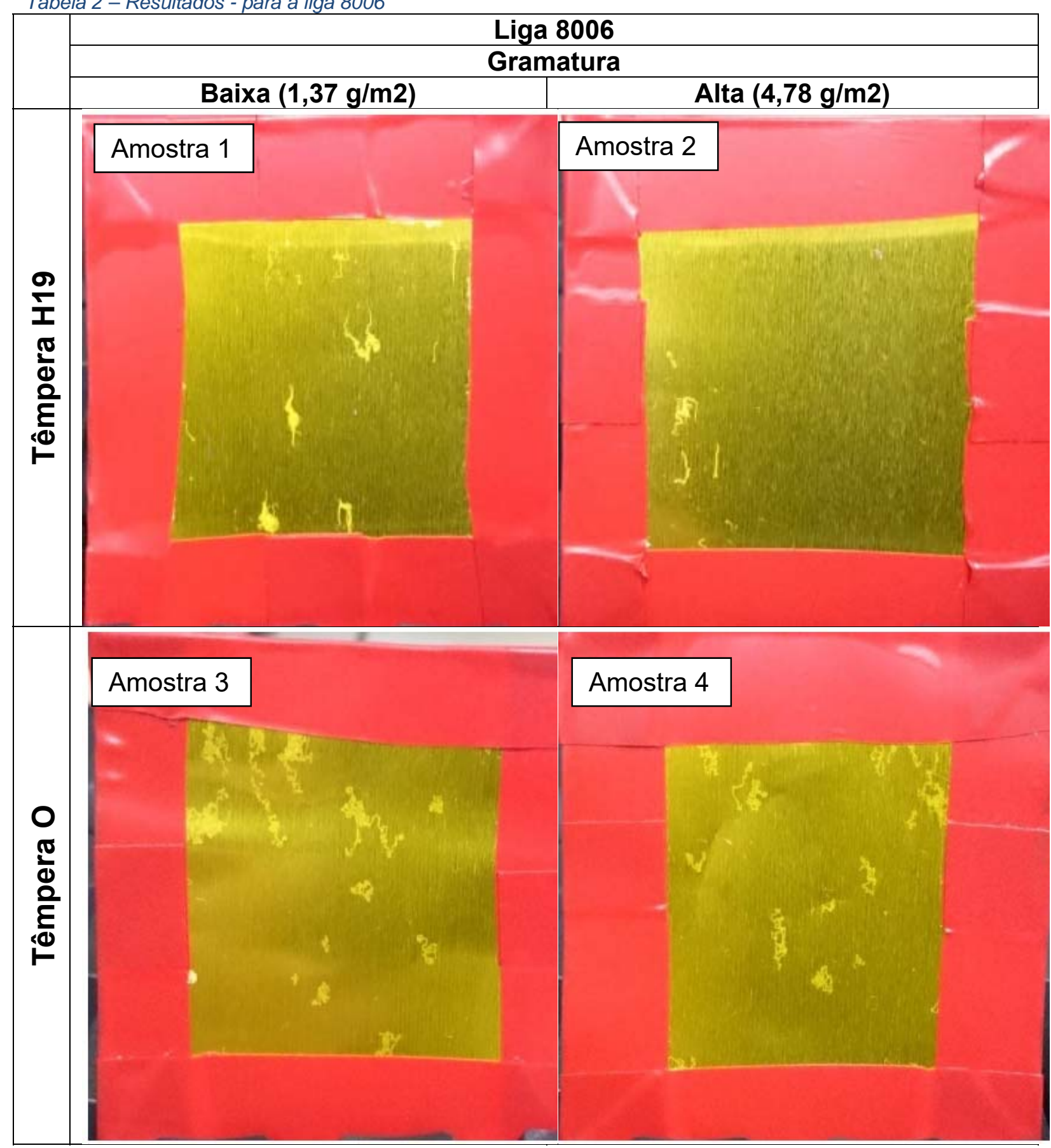

No microscópio ótico podemos verificar a corrosão filiforme em detalhes. Na figura 7 podemos ver a corrosão em três momentos de evolução e em todos os casos vemos que a corrosão se inicia por um ou mais pontos na superfície 


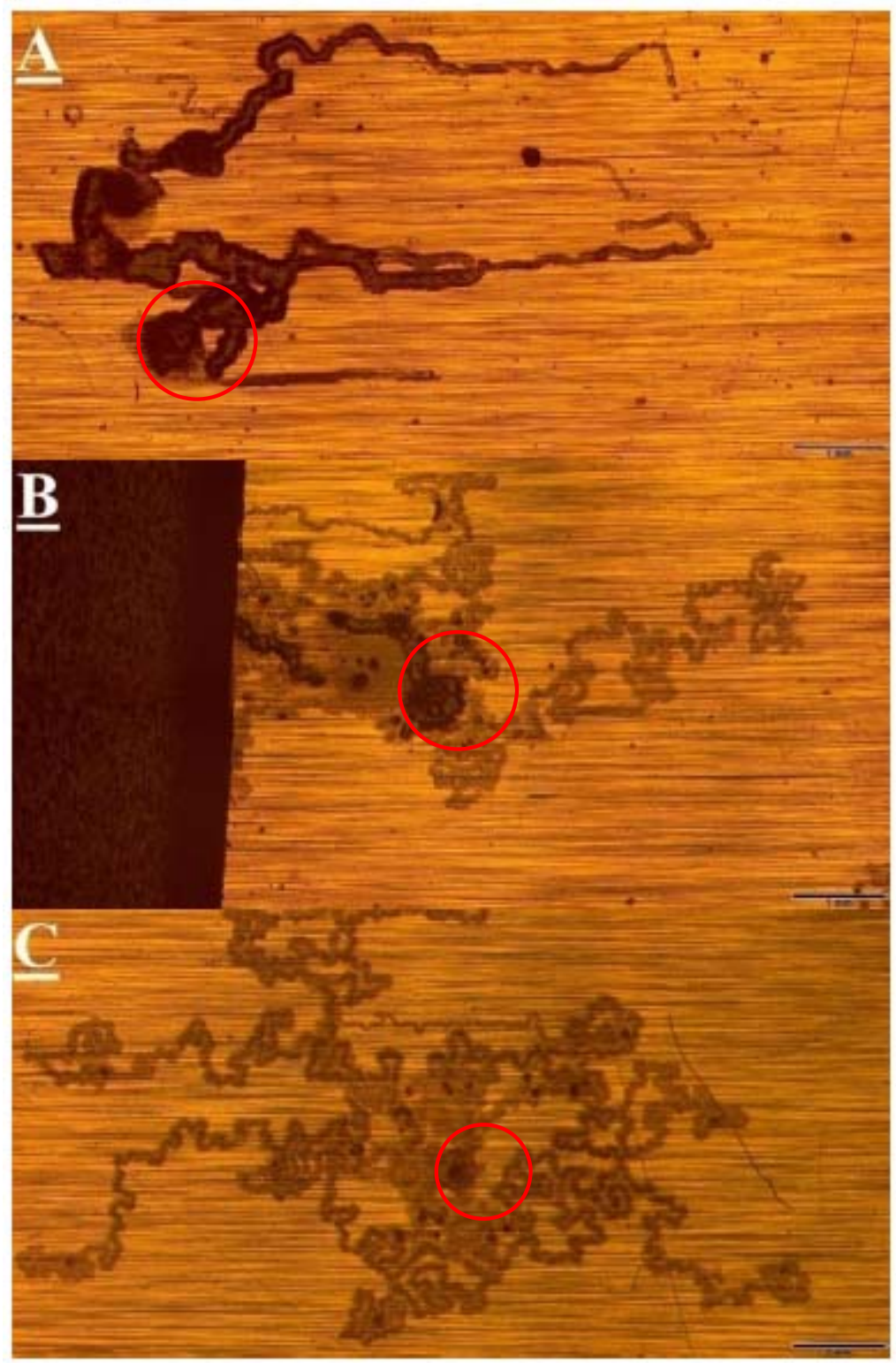

Figura 8 - Corrosão em três estágios

$\mathrm{Na}$ tabela 3 , as amostras de número 5 a 8 referentes a liga 8079 vemos que nenhuma apresentou corrosão visível a olho nu, apenas pequenos pontos quase imperceptíveis. 
Tabela 3 -Resultados para a liga 8079

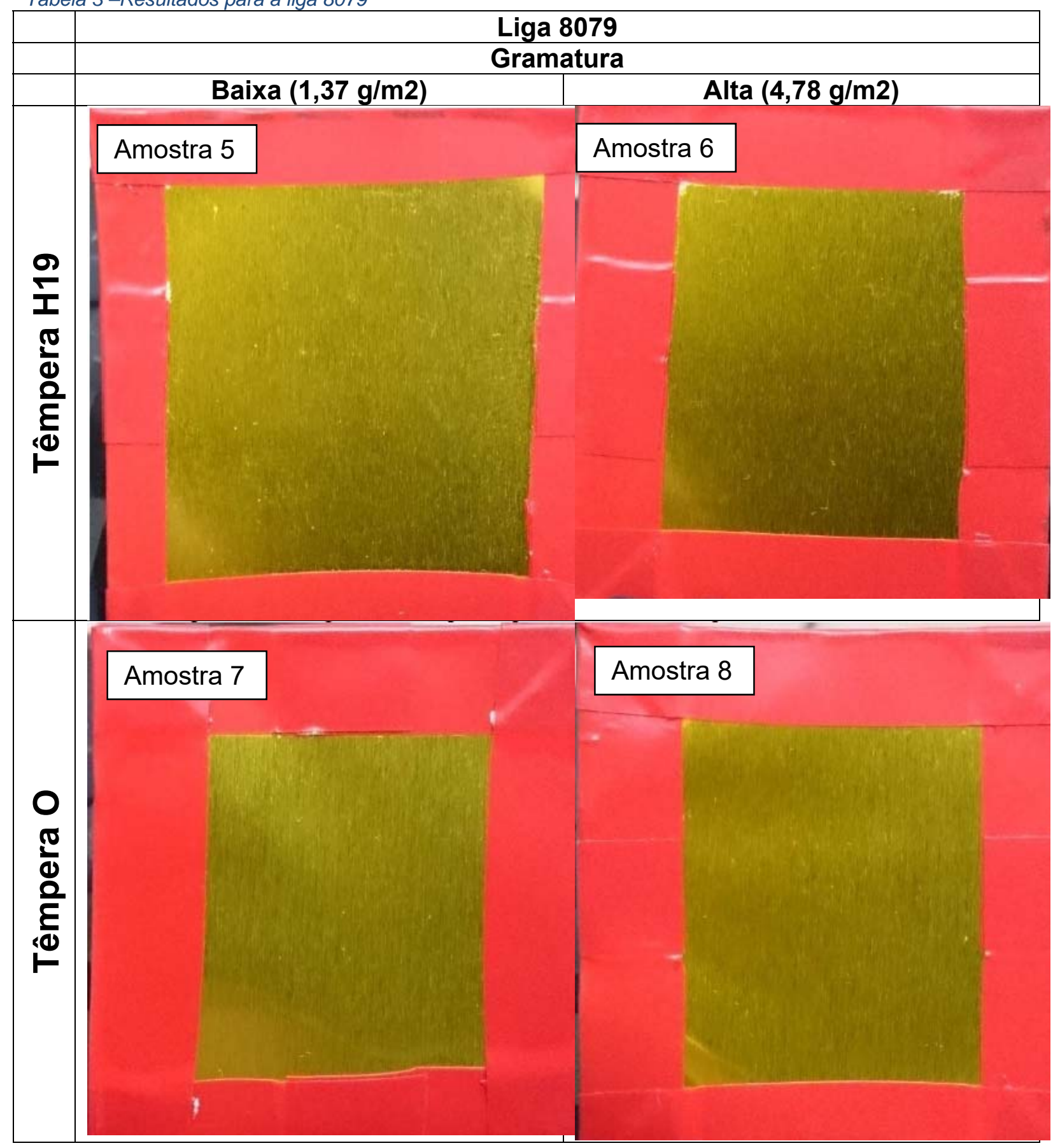

No microscópio ótico vemos pequenos pontos de corrosão filiforme porem sem muita evolução. 


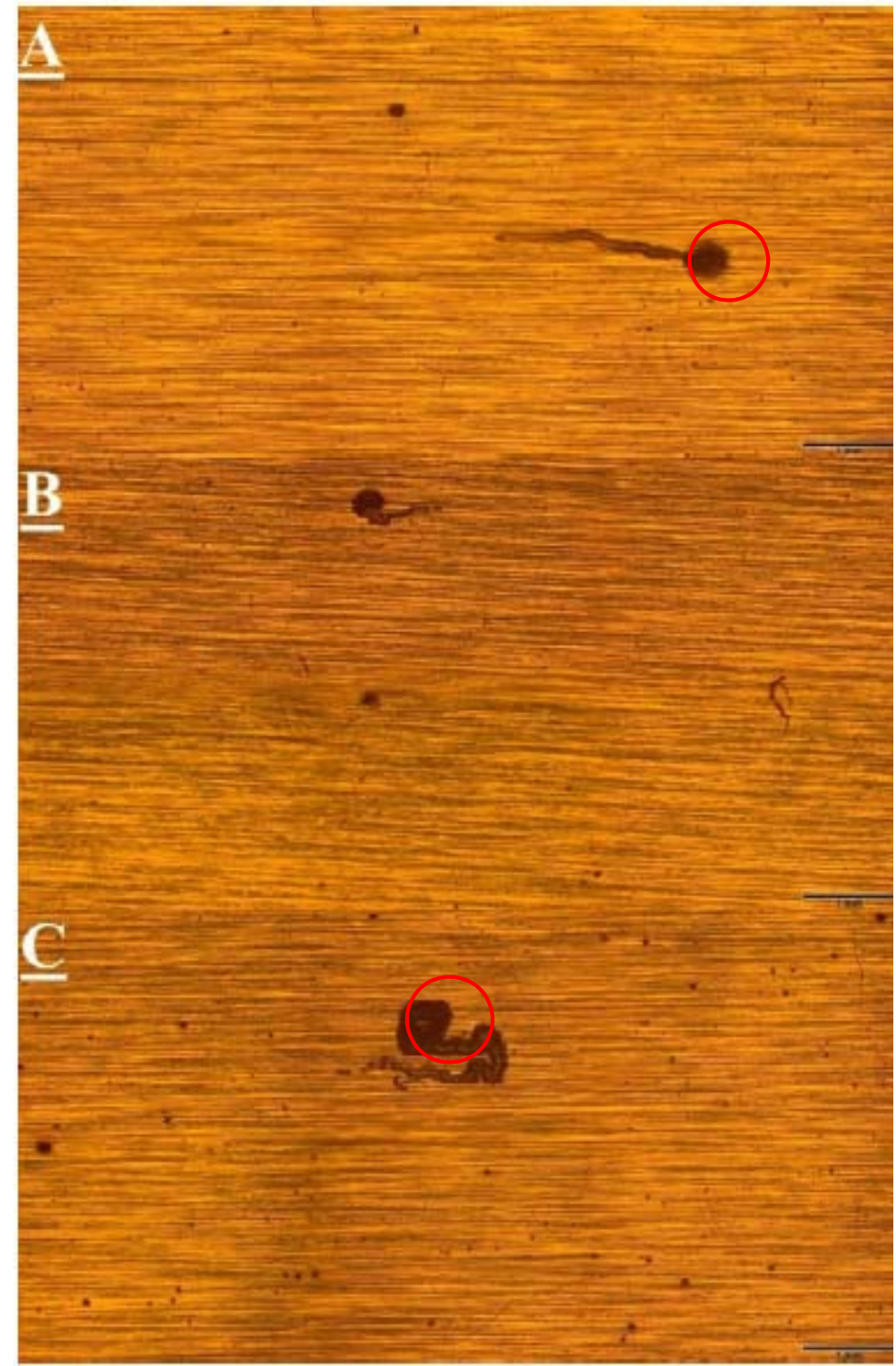

Figura 9 - Pontos de corrosão filiforme

\section{CONCLUSÃO}

A partir dos resultados verifica-se que a liga 8006 é mais suscetível a corrosão filiforme que a liga 8079, independente da tempera e da gramatura aplicada. Conforme G M SCAMANS isto pode ser explicado pela quantidade de Mn presente na liga 8006 o que torna interface epoxy / alumínio mais reativa que a liga 8079.

Podemos inferir através dos resultados que o revestimento não é uma barreira $100 \%$. Isto pode ser comprovado pelo fato de pequenos pontos de corrosão encontrados em todas as amostras. Estes pontos podem ter sido causados por falhas na camada do verniz tais quais trincas ou arranhados, como também pela permeabilidade da solução acida no verniz epoxy.

Diante dos fatos supracitados podemos concluir que para sistemas térmicos de troca de calor onde são usados revestimentos para o aumento da corrosão, a composição da liga deve ser levada em conta, pois, o efeito pode ser o contrário gerando uma situação de corrosão filiforme. 


\section{REFERÊNCIAS}

1 G M SCAMANS, G E THOMPSON, Y LIU AND X ZHOU Corrosion of Painted Aluminium Sheet

2 ROSA, L. de et al. The effect of a conversion layer and organic coating on the electrochemical behavior of 8006 and 8079 aluminum alloys. Elsevier. Naples, p. 153160. nov. 2001.

3 GENTIL, Vicente. Corrosão. 4. ed. Rio de Janeiro: Ltc, 2003.

$4 \quad$ G.S. Chen, M. Gao, R.P. Wei, Corrosion 52 (1996) 8.

5 LETH-OLSEN, Hakon; AFSETH, Andreas; NISANCIOGLU, Kemal. FILIFORM CORROSION OF ALUMINIUM SHEET. II. ELECTROCHEMICAL AND CORROSION BEHAVIOUR OF BARE SUBSTRATES. Pergamon. Trondheim, p. 1195-1214. jun. 1998.

6 MOREIRA, Waldomiro. Resinas Termofixas. In: ABAMACO. Compósitos I: Materiais, Processos, Aplicações, Desempenhos e Tendências. São Paulo: Abamaco, 2009. p. 36-88.

7 MUSA, Ahmed Y. (2012). Corrosion Protection of Al Alloys: Organic Coatings and Inhibitors, Recent Researches in Corrosion Evaluation and Protection, Prof. Reza Shoja 75

8 PONTE, Haroldo de Araújo. FUNDAMENTOS DA CORROSÃO. Curitiba: Universidade Federal do Paraná, 2003.

9 SHEASBY, P.g.; PINNER, R.. The Surface Treatment and Finishing of Aluminum and Its Alloys. 6. ed. Ohio: Asm International, 2001.

10 VARGEL, Christian. Corrosion of aluminium. Paris: Elsevier, 2004. 